\title{
CARACTERÍSTICAS FÍSICO-QUÍMICAS E CITOLÓGICAS DO LÍQUOR DE OVINOS SADIOS DA RAÇA SANTA INÊS
}

\author{
Jomel Francisco dos SANTOS ${ }^{1}$, MARCEla FiguerÊdo Duarte Moraes ${ }^{2}$, THIAGO ARCOVERDE \\ MaCieL $^{3}$, Paulo José Duarte-Neto ${ }^{4}$, CARla Lopes MendonÇA ${ }^{5}$, Daniela Oliveira ${ }^{5}$ \\ ${ }^{1}$ Pós-graduando da Universidade Federal Rural de Pernambuco, Recife, PE, Brasil. \\ ${ }^{2}$ Médica Veterinária, Unidade Acadêmica de Garanhuns, Universidade Federal Rural de Pernambuco, Recife, PE, Brasil. \\ ${ }^{3}$ Residente, Clínica de Bovinos de Garanhuns, Universidade Federal Rural de Pernambuco, Recife, PE, Brasil. \\ ${ }^{4}$ Professor Mestre da Universidade Federal Rural de Pernambuco, Recife, PE, Brasil. \\ ${ }^{5}$ Professoras Doutoras da Universidade Federal Rural de Pernambuco, Recife, PE, Brasil. danisjc6@yahoo.com.br
}

\begin{abstract}
A ocorrência de doenças neurológicas é elevada na clínica médica dos animais, porém poucos estudos documentam a composição normal do líquor de ovinos, em especial o da raça Santa Inês. O objetivo deste estudo foi o de estabelecer parâmetros de normalidade para as características físico-químicas e citológicas do líquor de ovinos desta raça. Para isso, foram utilizados 40 ovinos, com idades entre seis a dezoito meses, para a realização da punção lombossacral de líquor. Foi observado um padrão límpido e incolor, e a média para densidade foi de 1,006 $\pm 0,0064$, a concentração de proteínas foi de $25,27 \pm 6,64 \mathrm{mg} / \mathrm{dL}$ e a de glicose de $46,89 \pm 10,99 \mathrm{mg} / \mathrm{dL}$. Quanto às atividades enzimáticas,
\end{abstract}

foram observadas médias de $80,79 \pm 116,72 \mathrm{U} / \mathrm{L}$ para creatina quinase $(\mathrm{CK}) ; 17,43 \pm 11,91 \mathrm{U} / \mathrm{L}$ para lactato desidrogenase $(\mathrm{LDH})$ e $17,08 \pm 3,85 \mathrm{U} / \mathrm{L}$ para aspartato aminotransferase (AST). Os achados obtidos para contagem global de leucócitos foram de 4,61 \pm 4,96 células/ $\mu \mathrm{L}$ (0 a 15 linfócitos, 0 a 10 monócitos, 1 a 14 neutrófilos). Diante da carência de dados de referência para parâmetros do líquor de ovinos Santa Inês, sugere-se que os resultados obtidos nesta pesquisa sejam considerados valores normais na clínica de ovinos e, assim, contribuam no diagnóstico de doenças neurológicas nesta raça.

PALAVRAS-CHAVE: bioquímica; citologia; LCR; parâmetros fisiológicos; pequenos ruminantes.

\section{PHYSIOCHEMICAL AND CYTOLOGICAL CHARACTERISTICS OF THE CEREBROSPINAL FLUID OF HEALTHY SANTA INES OVINE ANIMALS}

\section{ABSTRACT}

The occurrence of neurological disease is widespread in clinical medicine of domestic animal, but there are few studies documenting the normal composition of cerebrospinal fluid (CSF) in ovine, especially Santa Ines breed. This study establishes the parameters for normal physiochemical and cytological analysis of cerebrospinal fluid as an aid for diagnosis of neurological disorders in this breed. For this, 40 adult ovine animals, aged between six and 18 months, were used for puncture of lumbosacral CSF. The aspect and color shower a clear and colorless pattern. The average density was $1.006 \pm 0.0064$, protein concentration was $25.27 \pm 6.64 \mathrm{mg} / \mathrm{dL}$ and glucose concentration was $46.89 \pm 10.99 \mathrm{mg} / \mathrm{dL}$. Enzymes had concentration averages of $116.72 \pm 80.79 \mathrm{U} / \mathrm{L}$ for creatine kinase; $17.43 \pm 11.91 \mathrm{U} / \mathrm{L}$ for lactate dehydrogenase and $17.08 \pm 3.85 \mathrm{U} / \mathrm{L}$ for aspartate aminotransferase. The results for the global cell count were $4.61 \pm 4.96$ leukocytes $/ \mu \mathrm{L}$ (0 to 15 lymphocytes, 0 to 10 monocytes, 1 to 14 neutrophils). Considering the lack of reference data for the physiochemical and cytological CSF analysis of Santa Ines ovine breed, it is recommended that the results obtained in this study are considered normal values for the breed. 
KEYWORDS: biochemistry; CFS; cytology; small ruminant; standard features.

\section{INTRODUÇÃO}

A raça Santa Inês tem se difundido no Brasil devido à sua rusticidade e produtividade nos mais diversos climas brasileiros. A carne, cada vez mais valorizada, chega a ultrapassar em até $50 \%$ o valor da carne bovina. Além disso, o alto valor de mercado da pele de ovinos deslanados se deve à sua maior elasticidade e resistência, associadas à textura fina, prestando-se para maior gama de aplicações na indústria de couros (SANTA INÊS, 2006).

Diversas doenças neurológicas acometem ovinos em todo o mundo como scrapie, a raiva e a forma neurológica da artrite-encefalite caprina (CAE), essa última apresentando-se como uma enfermidade de grande impacto na caprinoovinocultura mundial e, em especial, no Brasil, onde criação se encontra em franca ascensão. Além disso, os prejuízos econômicos e a questão da saúde pública que envolvem a raiva tornam o cuidado com essa enfermidade ainda mais importante por ser uma zoonose (RISSI et al., 2010).

A análise do líquor (líquido cefalorraquidiano ou cefalorraquiano, líquido cerebrospinal ou cerebroespinhal) é uma ferramenta importante no diagnóstico e estudo de doenças neurológicas (WELLES et al., 1992; PINHEIRO \& ALVES, 2000). O líquor banha a superfície do sistema nervoso central (SNC) e, por isso, a sua composição se altera de acordo com as diversas afecções do SNC (TVEDTEN, 1987). A sua análise é particularmente útil em se tratando da confirmação de lesão inflamatória envolvendo as leptomeninges, tal como a meningoencefalite bacteriana (SCOTT, 1995), além de refletir outros processos patológicos, inclusive do parênquima do SNC (MAYHEW \& BEAL, 1980). SCOTT (1993a) cita a meningoencefalite neonatal, a meningoencefalite causada por Listeria sp. e scrapie como neuropatias comuns em ovinos. PUGH (2004) relata que as causas de polioencefalomalácea em ovinos estão relacionadas a fatores nutricionais como alterações súbitas na dieta, alimentos com elevado teor de melaço, feno mofado, consumo de altos níveis de enxofre, ingestão de plantas tóxicas que contenham tiaminases (Pteridium aquilinum), acidose ruminal ou qualquer distúrbio nutricional que venha causar desequilíbrio no ambiente ruminal e, como consequência, na diminuição da população de bactérias produtoras de tiamina, no aumento da produção de tiaminase bacteriana e no ambiente ácido potencializando a atividade ruminal da tiaminase.

A análise do líquor é um dos melhores métodos na avaliação e diagnóstico das afecções do encéfalo e da medula espinhal, uma vez que alguns exames como tomografias computadorizadas e ressonâncias magnéticas são onerosos e de difícil acesso na clínica médica de ruminantes (RADOSTITIS et al., 2007). Assim, o exame do líquor é um teste importante para o diagnóstico antemortem de afecções que acometem o Sistema Nervoso Central (SNC), pois fornece informações fundamentais e, com treinamento e prática, oferece um mínimo de trauma aos animais, desde que colhido e analisado de maneira correta. Esse teste também deverá ser associado a exames post-mortem como histopatológico, toxicológico, entre outros, que podem ser utilizados na pesquisa e conclusão de diagnósticos diferenciais e definitivos das enfermidades do SNC (DIRKSEN et al., 1993; RADOSTITIS et al., 2007). É um método que apresenta limitações de uso em pacientes com risco anestésico evidente, coagulopatias graves, ou nos casos em que o animal apresentar aumento da pressão intra-craniana (LUCAS et al., 2008).

A ocorrência de doenças neurológicas é extensa na clínica médica dos animais domésticos, porém poucos estudos documentam a composição normal do líquor de ovinos, em especial os da raça Santa Inês, a qual tem se destacado economicamente no mercado de carne do Brasil. Portanto, este estudo pretende estabelecer os parâmetros normais para as características físico-químicas e citológicas do líquor de ovinos machos e fêmeas dessa raça.

\section{MATERIAL E MÉTODOS}

Foram coletadas amostras de líquor de 40 ovinos da raça Santa Inês, clinicamente sadios, sendo 20 machos e 20 fêmeas, com idade variando entre seis e 18 meses. Os animais foram contidos fisicamente e, após tricotomia da pele e rigorosa antissepsia, a cisterna lombossacral foi puncionada, de acordo com a técnica descrita por SCOTT (1993b).

As punções foram feitas com agulhas hipodérmicas descartáveis 1,20 x $40 \mathrm{~mm}$, 
posicionadas em ângulo de $90^{\circ}$, com a articulação lombossacral flexionada. A coleta foi realizada em três frascos estéreis sem EDTA ( 1 a $3 \mathrm{~mL}$ de líquor cada), sendo a terceira fração utilizada para as análises físicas (cor, aspecto e densidade) e citológicas (contagens global e diferencial de leucócitos) imediatamente após a coleta. A densidade foi analisada por meio de refratometria ${ }^{1}$ (PINHEIRO \& ALVES, 2000). Não foi acrescentado EDTA em nenhum dos frascos. As outras duas frações, destinadas às determinações das concentrações de glicose, proteína e enzimas, foram centrifugadas a 3.000 rotações por minuto durante 4 minutos, acondicionadas em tubos de vidro devidamente esterilizados contendo pelo menos 1 $\mathrm{mL}$ cada, identificadas e mantidas sob refrigeração a $4^{\circ} \mathrm{C}$ para a análise química.

As atividades enzimáticas da lactato desidrogenase $^{2}(\mathrm{LDH})$, da creatina quinase ${ }^{3}(\mathrm{CK})$ e da asparto aminotransferase $e^{4}$ (AST), assim como as concentrações de proteína ${ }^{5}$ e glicose $^{6}$ foram determinadas com o auxílio de kits comerciais e as leituras procedidas em analisador bioquímico semiautomático ${ }^{7}$, obedecendo rigorosamente aos padrões de teste estabelecidos pelo fabricante. A avaliação da glicose foi realizada logo após a coleta e centrifugação das amostras, minimizando a presença de hemácias, as quais poderiam alterar a concentração dessa substância. Com isso, os tubos utilizados não continham anticoagulante.

As contagens globais de leucócitos foram realizadas com o auxílio de câmara de FuchsRosenthal. A partir de uma alíquota de líquor obtida por um tubo capilar, a amostra foi depositada nos dois lados da câmara e, após 15 minutos, realizou-se a contagem com microscópio óptico usando a objetiva de 10x. O resultado da contagem foi dividido pelo fator 3, sendo expresso em $\mu \mathrm{L}$. De cada amostra foi realizada a análise diferencial, a partir de esfregaços obtidos de uma alíquota de $250 \mu \mathrm{L}$, proveniente da centrifugação das amostras em centrífuga citológica ${ }^{8}$ durante 5 minutos a 3000 rotações por minuto. Os esfregaços foram corados pelo método de Panótico rápido e a leitura das

\footnotetext{
${ }^{1}$ Portable refractometer, Quimis, Diadema, SP, Brasil

${ }^{2}$ LDH Liquiform (Labtest, Lagoa Santa, MG)

${ }^{3}$ CK NAC Liquiform (Labtest, Lagoa Santa, MG)

${ }^{4}$ AST/GOT Liquiform (Labtest, Lagoa Santa, MG)

${ }^{5}$ Sensiprot (Labtest, Lagoa Santa, MG)

${ }^{6}$ Glicose PAP Liquiform (Labtest, Lagoa Santa, MG)

${ }^{7}$ Labquest (Bioplus, São Paulo, SP)

${ }^{8}$ FANEM Modelo 248, São Paulo
}

lâminas foi realizada em microscópio óptico com objetiva de 100x.

Foi realizada estatística descritiva com apresentação dos parâmetros sexo, densidade, proteínas, glicose, LDH, CK, AST e contagens global e diferencial de leucócitos do líquor dos ovinos, com $95 \%$ de intervalo de confiança.

\section{RESULTADOS E DISCUSSÃO}

Optou-se pela realização da punção na cisterna lombossacral dos ovinos, que foi considerada de fácil acesso, além de conferir qualidade satisfatória ao exame do líquor coletado. Isso está em conformidade com WELLES et al. (1992) e SCOTT \& WILL (1991), que consideraram a punção da cisterna lombossacral segura e de fácil execução.

De acordo com PINHEIRO \& ALVES (2000), sedação nem sempre é necessária para a punção de líquor em ovinos e a contenção física foi realizada posicionando o animal em decúbito lateral, com a pelve flexionada e os membros pélvicos estendidos nas laterais do abdome. A cabeça do animal foi direcionada contra o flanco, seguindo a técnica relatada por SCOTT (2010).

A coleta foi realizada em três frascos estéreis sem EDTA (1 a $3 \mathrm{~mL}$ de líquor cada) a fim de minimizar os riscos de contaminação com sangue, conforme recomendação de PELLEGRINO et al. (2003). A centrifugação do líquor para a análise química foi necessária para evitar o consumo de substâncias, como a glicose, pelas hemácias, se estivessem presentes, ainda que em número mínimo.

Das 40 amostras de líquor, 37 (92,5\%) apresentaram-se incolores e límpidas. Tais achados concordam com os de TVEDTEN (1987), que verificaram amostras liquóricas de bovinos sadios igualmente incolores e límpidas. Em três animais (7,5\% da amostra), o líquor colhido apresentava-se com coloração rósea e turvo. Essa hemorragia discreta observada pode ser atribuída à punção acidental de vasos sanguíneos, fato também relatado por BAILEY \& VERNAU (1997); contudo, não se observaram quaisquer alterações clínicas nesses e nos demais ovinos deste experimento. 
Tabela 1 - Valores das médias, intervalo de confiança (I.C.), desvios-padrão (D.P.) e valores mínimo (Mín.) e máximo (Máx.) obtidos para densidade, proteínas totais, glicose, creatina quinase (CK), lactato desidrogenase (LDH) e aspartato aminotransferase (AST) e contagens global e diferencial de leucócitos do líquor de ovinos Santa Inês sadios

\begin{tabular}{|c|c|c|c|c|c|c|}
\hline & \multirow[t]{2}{*}{ Média } & \multicolumn{2}{|c|}{ I.C. $(95 \%)$} & \multirow[t]{2}{*}{ D.P. } & \multirow[t]{2}{*}{ Mín. } & \multirow[t]{2}{*}{ Máx. } \\
\hline & & LI & $\overline{\mathrm{LS}}$ & & & \\
\hline Densidade (g/dL) & 1,0046 & 1,005 & 1,006 & 0,0064 & 1,004 & 1,007 \\
\hline Proteínas totais $(\mathrm{mg} / \mathrm{dL})$ & 25,27 & 23,38 & 27,35 & 6,64 & 12,73 & 38,88 \\
\hline Glicose (mg/dL) & 46,89 & 43,45 & 50,02 & 10,99 & 24,50 & 67,23 \\
\hline CK (U/L) & 80,79 & 55,76 & 135,10 & 116,72 & 0,00 & 680,00 \\
\hline $\mathrm{LDH}(\mathrm{U} / \mathrm{L})$ & 17,43 & 14,45 & 21,87 & 11,91 & 0,00 & 60,70 \\
\hline AST (U/L) & 17,08 & 15,96 & 18,33 & 3,85 & 10,48 & 26,19 \\
\hline Contagem global $(/ \mu \mathrm{L})$ & 4,61 & 3,02 & 6,20 & 4,96 & 0,0 & 20,00 \\
\hline Linfócitos $(/ \mu \mathrm{L})$ & 4,64 & 3,32 & 5,95 & 4,11 & 0,0 & 15,00 \\
\hline Neutrófilos $(/ \mu \mathrm{L})$ & 4,40 & 3,51 & 5,29 & 2,97 & 1,00 & 14,00 \\
\hline Monócitos $(/ \mu \mathrm{L})$ & 1,69 & 1,03 & 2,34 & 2,05 & 0,0 & 10,00 \\
\hline
\end{tabular}

$\mathrm{LS}=$ limite superior; $\mathrm{LI}=$ limite inferior.

Os valores mínimo e máximo encontrados para densidade do líquor de ovinos Santa Inês (Tabela 1) corroboram com os descritos por PINHEIRO \& ALVES (2000) para caprinos (1,004 a 1,006; média de 1,0046). SCOTT (2010) afirma que a densidade do líquor de ovinos deve ser menor do que 1,010 e esse dado não é suficientemente preciso e útil para diagnosticar doenças neurológicas nesta espécie.

Em relação às proteínas (Tabela 1), os valores encontrados estão abaixo dos valores descritos por WELLES et al. (1992), para bovinos adultos (média de 39,2 mg/dL), e por PUGH (2004), para ovinos (29 a $42 \mathrm{mg} / \mathrm{dL}$ ). Essas variações podem estar relacionadas a fatores como espécie animal, sexo, raça e idade dos animais examinados. SCOTT \& WILL (1991) observaram que o nível proteico estava aumentado em ovinos com abscesso epidural e acrescentaram que a punção lombar foi um método que permitiu a identificação da afecção. Entretanto, SCOTT (1993c) não observou correlação entre severidade de sintomas neurológicos na listeriose de ovinos com a concentração de proteína no líquor e não houve alterações nos parâmetros do líquor puncionado na região lombossacral.

A média encontrada para glicose no líquor de ovinos Santa Inês (Tabela 1) apresentou-se menor que a observada por PINHEIRO \& ALVES (2000) em caprinos (100 mg/dL) e por PUGH (2004) em ovinos (52 a $85 \mathrm{mg} / \mathrm{dL}$ ). No entanto, a concentração de glicose dos ovinos não se distanciou da descrita por WELLES et al. (1992) para bovinos adultos (37 a $51 \mathrm{mg} / \mathrm{dL}$; média de $42,8 \mathrm{mg} / \mathrm{dL}$ ).

WELLES et al. (1992) observaram, em 16 bovinos sadios, valores médios de CK de 11,438 U/L, valores mínimo e máximo de 2 a 48 U/L e intervalo de confiança de 4,124 a 18,751 U/L, com valores numéricos menores do que os de ovinos (Tabela 1). Comparando as concentrações séricas e liquóricas de CK, WELLES et al. (1992) não encontraram correlação entre ambas; entretanto, a enzima identificada no líquor teve maior especificidade e sensibilidade para o diagnóstico de doenças que afetam o SNC e a atividade da CK foi considerada dependente da presença de eritrócitos no líquor.

A atividade enzimática de LDH (Tabela 1) em líquor de ovinos Santa Inês apresentou média semelhante aos achados de WELLES et al. (1992) em bovinos sadios (média de 13,938 U/L, valores mínimo de 2, máximo de 25 e intervalo de confiança de 11,129 a 16,747 U/L). Esses autores acrescentam que a atividade dos níveis liquóricos de LDH é marcantemente menor do que a da LDH sérica. AMINLARI \& MEHRAN (1988) encontraram média de $8,7 \pm 6,1 \mathrm{UI} / \mathrm{L}$ de $\mathrm{LDH}$ em líquor de ovinos, o que representa de 5 a $10 \%$ das concentrações séricas desta enzima.

Para a AST, a média encontrada no líquor de ovinos da raça Santa Inês foi de 17,08 \pm 3,85 U/L (Tabela 1), enquanto que AMINLARI \& MEHRAN (1988) observaram atividade enzimática de AST de $80,2 \pm 8,9 \mathrm{UI} / \mathrm{L}$, significativamente menor que as concentrações séricas.

Durante a contagem global de leucócitos (Tabela 1) no líquor de ovinos da raça Santa Inês, observou-se presença de eritrócitos em 10\% das amostras. Apesar de existir discordância na literatura 
em relação ao número total de leucócitos presentes em líquor normal, alguns autores concordam que esse número deve ser menor que 8 leucócitos/ $\mu \mathrm{L}$ (WELLES et al., 1992; BAILEY \& VERNAU, 1997). Sua determinação é valiosa no diagnóstico de processos inflamatórios, irritativos ou infecciosos do sistema nervoso central, já que, nesses casos, pode ocorrer aumento do número total dessas células (TIPOLD, 2002; FEITOSA et al., 2005; FLEURY, 2009).

Com relação à contagem diferencial de leucócitos, os achados observados nesta pesquisa indicaram tanto a presença de células mononucleadas quanto de polimorfonucleares no líquor de ovinos Santa Inês, todavia, em quantidades pequenas. Dentre as mononucleadas observadas, os linfócitos prevaleceram em relação aos monócitos, o que também foi mencionado por MAYHEW \& BEAL (1980). Dentre os polimorfonucleares, apenas neutrófilos foram identificados. De acordo com LORENZ \& KORNEGAY (2006), as contagens global e diferencial de leucócitos é o evento mais importante da análise do líquor. Conforme esses autores, a contagem aumentada de leucócitos e a elevação da concentração proteica correlacionam-se com a ocorrência de doenças neurológicas, inclusive quando as amostras contém quantidades moderadas de sangue.

\section{CONCLUSÃO}

Sugere-se que os valores do líquor de ovinos Santa Inês sadios encontrados sejam considerados normais na clínica de ovinos, contribuindo, assim, para o diagnóstico de doenças neurológicas nesta raça.

\section{AGRADECIMENTOS}

Agradecemos ao $\mathrm{CNPq}$ pela bolsa PIBIC concedida. Agradecemos também ao professor Doutor José Wanderley Cattelan e à professora Doutora Silvana Martinez Baraldi Artoni, ambos da Unesp, Campus Jaboticabal, pela revisão do manuscrito.

\section{REFERÊNCIAS}

AMINLARI, M.; MEHRAN, M.M. Biochemical properties of cerebrospinal fluid of sheep and goat. Comparison with blood. Journal of Veterinary Medicine, Series A, v. 35, n. 4, p. 315-319, 1988.

BAILEY, C.S; VERNAU, W. Cerebrospinal fluid. In: Clinical Biochemistry of domestic animals. KARENO, J. J; HARVEY, J.W.; BROSS, M.L. San Diego:
Academic Press, 1997. 932p

DIRKSEN, G.; GRÜNDER, H.-D.; STÖBER, M. Rosenberger: Exame clínico dos bovinos. 3 ed. Rio de Janeiro: Guanabara Koogan, 1993. 419 p.

FEITOSA, M. M.; IKEDA, F.A.; BONELO, F.L.; CIARLINI, P.C.; GONÇALVES, M.E.; LIMA, V.M.F.; PERRI, S.H.V. Avaliação liquórica de cães, com e sem sintomatologia neurológica, naturalmente acometidos por Leishmaniose Visceral. Veterinária Notícias, Uberlândia, v. 11, n. 2, p. 61-69, 2005.

FLEURY. Líquido Cefalorraquidiano. Disponível em: <http://www.fleury.com.br/Pages/Default.aspx>.

Acessado em: 22 jan. 2009.

LORENZ, M.D.; KORNEGAY, J.N. Neurologia Veterinária. São Paulo: Manole, 2006.

LUCAS, R.A.P.; GODOY, R.C.; SACCO, S.R. Análise do líquido cefalorraquidiano em pequenos animais. Revista Científica Eletrônica de Medicina Veterinária. Ano VI, n. 11, 2008. Disponível em: $<\mathrm{http} / / / \mathrm{ww} w$. revista.inf.br/veterinaria11/revisao/edic -vi-n11-RL05.pdf>. Acesso em: 01 dez. 2010.

MAYHEW, I.G.; BEAL, C.R. Techniques of analysis of cerebrospinal fluid. Veterinary Clinics of North America. v. 10, p. 155-176, 1980.

PELLEGRINO, F; SURANTI, A., GARIBALDI, L. Síndromes neurológicas em cães e gatos. São Caetano do Sul: Interbook, 2003.

PINHEIRO, R.R.; ALVES, F.S.F. Valores de alguns components do líquido cefalorraquiano em caprinos no semi-árido do nordeste do Brasil. Revista Brasileira de Medicina Veterinária, v. 22, n. 6, p. 246-247, 2000.

PUGH, D.G. Clínica de ovinos e caprinos. São Paulo: Roca, 2004. 528 p.

RADOSTITS, O.M.; GAY, C.C; HINCHCLIFF, K.W.; CONSTABLE, P.D. Veterinary medicine: a textbook of diseases of cattle, horses, sheep, pigs and goats. 10 ed. Edingburg: Saunders, 2007. 2156 p.

RISSI， D.R.; FIGHERA， R.A.; IRIGOYEN， L.F.; KOMMERS, G.D.; BARROS, C.S.L. Doenças neurológicas de ovinos da região central do Rio Grande do Sul. Pesquisa Veterinária Brasileira, v. 30, n. 3, p. 222228, 2010.

SANTA INÊS, A raça, 2006. Disponível em: $<\mathrm{http} / / / \mathrm{www}$.acrimat.com.br/institucional/index.asp? cod=11>. Acessado em: 24 jan. 2008.

SCOTT, P.R. A field study of ovine listerial meningoencephalitis with particular reference to cerebrospinal fluid analysis as an aid to diagnosis and prognosis. British Veterinary Journal, v. 149, n.2, p. 165-170, 1993c.

SCOTT, P.R. Cerebrospinal fluid collection and analysis in suspected sheep neurological disease. Small Ruminant Research, v. 92, p. 96-103, 2010.

SCOTT, P.R. Collection and interpretation of 
cerebrospinal fluid in ruminants. In Practice, v. 5, p. 298300, $1993 \mathrm{~b}$.

SCOTT, P.R. The collection and analysis of cerebrospinal fluid as an aid to diagnosis in ruminant neurological disease. British Veterinary Journal, v. 151, n. 6, p. 603614, 1995.

SCOTT, P.R. Total protein and electrophoretic pattern of cerebrospinal fluid in sheep with some common neurological disorders. Cornell Veterinary, v. 83, n. 3, p. 199-204, 1993a.

SCOTT, P.R.; WILL, R.G. A report of Froin's syndrome in five ovine thoracolumbar epidural abscess cases. British Veterinary Journal, v. 147, n. 6, p. 582-584,
1991.

TIPOLD, A. Cerebrospinal Fluid. In: K.G. Braund (Ed.). Clinical neurology in small animals - localization, diagnosis and treatment. Ithaca: International Veterinary Information Service, 2002. 30 p.

TVEDTEN, H.W. Clinical pathology of bovine neurologic disease. Veterinary Clinics of North America: Food Animal Practice, v. 3, n. 1, p. 25-44, 1987.

WELLES, E.G.; TYLER, J.W.; SORJONEN, D.C.; WHATLEY, E.M. Composition and analysis of cerebrospinal fluid in clinically normal adult cattle. American Journal of Veterinary Research, v. 53, n. 11, p. $2050-2057,1992$. 